\title{
La sextorsión como nueva modalidad de corrupción en el servicio público
}

Sextortion as a new form of corruption in the public service

Sextorção como nova forma de corrupção no serviço público

\author{
Luis Eduardo Ramírez Sirgo \\ 1sirgo@docentes.uat.edu.mx \\ Universidad Autónoma de Tamaulipas - México \\ https://orcid.org/0000-0003-4511-7678
}

\section{Verónica Mireya Moreno Rodríguez}

vmmoreno@docentes.uat.edu.mx

Universidad Autónoma de Tamaulipas - México https://orcid.org/0000-0003-4276-4271

Ernesto Casas Cárdenas

ecasas@docentes.uat.edu.mx

Universidad Autónoma de Tamaulipas - México

https://orcid.org/0000-0003-3205-1091

\section{RESUMEN}

Los actos de corrupción, por el simple hecho de existir, generan descontento en la sociedad por el abuso que hacen los servidores públicos del poder que se les otorga. El hecho de tomar ventaja de una posición jerárquica para obtener un beneficio particular representa una flagrante violación a los valores éticos y morales, sin dejar pasar por alto que se encuentran tipificados como ilícitos en la ley. Si este fenómeno, que ya de por sí, afecta a la sociedad de muy diversas maneras, cuando se le agrega un nuevo elemento como lo es el solicitar favores sexuales a cambio de un servicio público, no sólo se limita ya a un acto de corrupción de los que ampliamente se han abordado en la literatura especializada, sino que se trata de una corrupción con perspectiva de género y que afecta de manera específica y diferente a éste. No obstante que la sextorsión actualmente se relaciona con la difusión de imágenes y videos de índole sexual para generar perjuicio a una persona, este artículo tiene como objetivo exponer, a través de un análisis documental de artículos científicos, reportes de investigación de instancias internacionales y notas periodísticas una modalidad de la sextorsión diferente a la que se contempla actualmente, a fin de ofrecer una visión más amplia de este fenómeno, y generar políticas públicas que permitan avanzar en el tema en Tamaulipas.

Palabras clave: Corrupción, sextorsión, abuso de poder.

\begin{abstract}
Acts of corruption, by the simple fact of existing, generate discontent in society due to the abuse that public servants make of the power that is granted to them. The fact of taking advantage of a hierarchical position to obtain a particular benefit represents a flagrant violation of ethical and moral values, without overlooking the fact that they are considered as illegal in the criminal law. When this phenomenon adds a new element, such as requesting sexual favors in exchange for a public service, it is not only limited to an act of corruption of those that have been widely addressed in the specialized literature, but a new kind of corruption with a gender perspective. Despite the fact that sextortion is currently related to the dissemination of images and videos of a sexual nature to cause harm to a person, this article aims to expose, through a documentary analysis of scientific articles, research reports from international bodies and journalistic notes, a new modality of sextortion different from the one currently contemplated, this towards to offer a broader vision of this phenomenon, and generate public policies that allow further research on the issue in Tamaulipas.
\end{abstract}

Keywords: Corruption, sextortion, abuse of power.

RESUMO 
Os atos de corrupção, pelo simples fato de existirem, geram descontentamento na sociedade pelo abuso que os servidores públicos fazem do poder que lhes é concedido. O fato de se aproveitar de uma posição hierárquica para obter determinado benefício representa uma flagrante violação dos valores éticos e morais, sem deixar de lado o fato de serem classificados como ilegais pela lei. Se esse fenômeno, que por si só, atinge a sociedade de formas muito diversas, quando se agrega um novo elemento, como a solicitação de favores sexuais em troca de um serviço público, não se limita apenas a um ato de corrupção. Amplamente abordado na literatura especializada, é a corrupção com perspectiva de gênero e que a afeta de forma específica e diferenciada. Apesar de a sextorção estar atualmente relacionada à divulgação de imagens e vídeos de natureza sexual para causar danos a uma pessoa, este artigo tem como objetivo expor, por meio de uma análise documental de artigos científicos, relatórios de pesquisas de organismos internacionais e notas jornalísticas da modalidade. De sextorção diferente da atualmente contemplada, a fim de oferecer uma visão mais ampla deste fenômeno, e gerar políticas públicas que permitam avançar sobre o tema em Tamaulipas.

Palavras chave: Corrupção, sextorção, abuso de poder.

\section{INTRODUCCIÓN}

$\mathrm{Al}$ hacer referencia a la palabra corrupción, se puede relacionar con una situación indebida, incorrecta, ilegal, no aceptada, condenada y fuera del contexto de lo que debe ser, es decir, todo aquello a lo que no corresponde a lo previamente establecido por las buenas costumbres, los valores y la aceptación general. Los medios de información incluyen constantemente noticias sobre desvíos de recursos, enriquecimiento inexplicable de servidores públicos, el otorgamiento de contratos multimillonarios empresas relacionadas a altos funcionarios del gobierno, las acusaciones contra ex gobernadores y funcionarios de alto nivel, por sólo mencionar algunos ejemplos. Los actos de corrupción dentro de la administración pública ocurren en todos niveles, desde el personal del nivel operativo hasta las más altas jerarquías a grado de secretarios, gobernadores, incluso al Presidente.

El grado en que la corrupción afecta a la sociedad es ilimitado y representa el mayor impedimento en la concreción del desarrollo sostenible de las regiones. Diversas investigaciones han demostrado que la corrupción ocasiona varias consecuencias, tales como la exacerbación de la pobreza y la afectación negativa al crecimiento económico, tiene un efecto debilitante en el desarrollo de las regiones con riqueza en recursos naturales, incrementa el conflicto y es un obstáculo para la consolidación de la paz, afecta la entrega de ayuda humanitaria, comparte nexos con el crimen organizado, afecta los derechos humanos e impulsa un ambiente antidemocrático (ONU, 2008).

La corrupción por tanto, expende sus efectos hacia todos los sentidos, pues propicia ineficiencias en proporcionar los servicios públicos, no sólo en la perspectiva del ejercicio del gasto público, sino también en modificar las decisiones de los servidores públicos hacia sectores o actividades en las cuales puedan obtener beneficios indebidos (Warren, 2004); genera un aumento a la tolerancia a la oferta y aceptación de sobornos en las instituciones públicas, lo que su vez debilita aún más la confianza de los ciudadanos en ellas (Habibov, Afandi, \& Cheung, 2017); los gobiernos tienden a ver disminuida su capacidad recaudatoria fiscal y utilizan los fondos públicos de manera menos eficiente (Dzhumashev, 2014); afecta el gasto del gobierno, reduce la inversión y el capital humano, al igual que implica una relación negativa con la estabilidad política (Ghalwash, 2014). Conforme a lo abordado, la corrupción puede manifestarse de diferentes formas, pero todas confluyen en generar un beneficio particular o de grupos definidos a costa de un daño o menoscabo en el interés colectivo.

De forma enunciativa, más no limitativa en materia de salud, este fenómeno se manifiesta en la falta de medicamentos disponibles en los hospitales debido a las redes que implican a servidores públicos, proveedores y laboratorios de investigación; en el caso de la impartición de justicia, al momento en que las partes deben entregar dádivas a los juzgadores para impulsar los 
procedimientos judiciales, incluso, para sesgar el dictado de sentencias o su dilación; en materia de educación, en la falta de procedimientos transparentes y la venta de plazas para nuevos maestros, la contratación de personas que no cumplen con un perfil académico o el limitar derecho al acceso a la educación si no se paga una cuota "voluntaria"; en cuestión de obras públicas, al solicitar al contratista un porcentaje del contrato sujeto a licitación, que ocasiona la reducción de la calidad de los materiales utilizados e implica un riesgo para los ciudadanos.

No es óbice el afirmar que el fenómeno de la corrupción afecta de manera negativa la legitimidad de las instituciones que integran la administración pública (federal, estatal o municipal), pues los recursos humanos, materiales y financieros se desvían del cumplimiento de su función principal hacia la satisfacción de intereses particulares, como lo son el enriquecimiento o la perpetuación en el poder. La corrupción puede sufrirse de manera distinta entre hombres y mujeres, es decir, que el hecho de pertenecer a un género determinado incide en el nivel de afectación que puede tenerse por estas prácticas, esto debido a que en muchos aspectos las mujeres son sujetas a las mismas formas de corrupción que los hombres, sin embargo, en una mayor medida los efectos negativos se exacerban por cuestiones de relaciones de poder, discriminación y vulnerabilidad (SIDA, 2015). Dichas formas de corrupción se centran en la extorsión sexual, los ataques a la dignidad y el tráfico de humanos (Transparency international, 2014).

Cuando los servidores públicos abusan de su poder para obtener beneficios económicos, es ampliamente conocido que están llevando a cabo una práctica corrupta, lo que impulsa una acción de autoridades competentes y deviene en sanciones penales o administrativas. Sin embargo, cuando un elemento distinto hace presencia, que en este caso es el sexo, no siempre se reconoce como un acto de corrupción y, por tanto, no se procede a denunciarse y mucho menos a castigarse. Este tipo de actos, considerado como una modalidad de la sextorsión, reúne las características de la definición de corrupción, como lo es "el abuso del poder para un beneficio privado" formuladas (World Bank, s/f) y Transparencia Internacional (Transparency International, 2009), sin embargo sigue sin ser contemplado en la legislación y en la agenda pública, lo que permite su continuación impune.

La problemática antes aludida escapa de la vista de la sociedad, por el hecho de que la sextorsión - en la modalidad que se aborda en el presente documento - a menudo no se denuncia por evitar el estigma social que caracteriza este tipo de actos, el temor de represalias, así como además la dificultad que implica el demostrar con pruebas el comportamiento del perpetrador, lo que disminuye la posibilidad que la víctima sea escuchada y se haga justicia.

De acuerdo al Barómetro Global de Corrupción (BGC) para Latinoamérica y el caribe 2019 (Transparency International, 2019), la corrupción obstaculiza el crecimiento económico y la prestación de servicios públicos y en algunos casos priva a las personas de sus derechos humanos y su dignidad. Esa dignidad que se pierde cuando las personas son coaccionadas a proveer favores sexuales a cambio de servicios públicos, tales como salud y educación.

El Barómetro presenta un conjunto de datos amplio y detallado concernientes a las opiniones de los ciudadanos sobre la corrupción, así como experiencias directas con el soborno. Entre enero y marzo de 2019, se aplicaron encuestas a más de 170,000 ciudadanos en 18 países de la región. Conforme a los resultados obtenidos por el BGC, la corrupción afecta más fuerte a los más vulnerables; en este caso a las mujeres, quienes son más propensas a pagar sobornos por los servicios básicos que proporciona el Estado.

Dentro de los hallazgos más importantes del estudio, en lo que respecta a la extorsión sexual - de aquí en adelante llamada sextorsión -, sobresale que una de cada cinco personas ha 
experimentado dicha situación para el acceso a los servicios proporcionados por el gobierno, o conoce a alguien que lo ha sufrido.

Por primera vez, los resultados obtenidos por el Barómetro hacen énfasis en los datos sobre sextorsión, una de las formas más significativas de la corrupción de género. Los países con un mayor porcentaje de incidencia de casos son Barbados (30\%), Bahamas (24\%), Guatemala (23\%) y Guyana (22\%), mientras que México ocupa el quinto lugar con un 20\%, junto con Brasil y Perú. Un dato que sobresale es que más del $72 \%$ de los encuestados consideran que la sextorsión sucede al menos ocasionalmente y el $8 \%$ restante, que nunca ocurre.

En este contexto, el presente artículo busca exponer el fenómeno de la sextorsión desde la perspectiva conceptual a través de un análisis de fuentes secundarias tales como artículos científicos, reportes de investigación de instancias internacionales y notas periodísticas, como una modalidad de corrupción distinta a la forma se ha abordado actualmente en la legislación mexicana, es decir, sin contemplar la difusión imágenes o videos de contenido sexual por medio de las Tecnologías de Información y Comunicación (TIC's), a fin de que se pueda ofrecer una visión más amplia de este fenómeno, y generen políticas públicas que permitan avanzar en el tema en Tamaulipas.

\section{FUNDAMENTACIÓN TEÓRICA}

\subsection{El concepto de corrupción.}

Dentro de las negociaciones llevadas a cabo en la firma y ratificación de la Convención de las Naciones Unidas Contra la Corrupción ${ }^{1}$, mismas que se relatan en el Manual de las Naciones Unidas en Medidas Prácticas de Anti-Corrupción para Fiscales e Investigadores (UNDOC, 2004), sobresale el hecho de que no existe una definición comprensible y universalmente aceptada sobre corrupción, ya que - como se verá más adelante - las definiciones identificadas en la literatura son variaciones de "el uso de una posición pública o privada para el beneficio directo o indirecto".

Asimismo, este documento relata que los intentos para desarrollar una definición más precisa, encuentran invariablemente problemas legales, criminológicos y políticos. Cuando las negociaciones de esta Convención iniciaron en 2002, una opción que se tomó en consideración fue de evitar el problema de definir la corrupción listando una serie de tipos específicos o actos de corrupción. En ese sentido, a efecto de proporcionar materia de análisis conceptual de este fenómeno, se considera necesario incluir las definiciones más utilizadas en la literatura especializada en el tema.

Conforme lo anterior, diversas organizaciones internacionales han establecido una definición de este fenómeno, de las que destacan las formuladas por el Banco Mundial (World Bank, s/f) y Transparencia Internacional (TI, s.f.), quienes confluyen que corrupción es el abuso del servicio público encomendado para un beneficio propio ${ }^{2}$, es por tanto, que se considera corrupción todo acto que deriva en un aprovechamiento directo o indirecto para un servidor público, considerando la ventaja que le otorga el ocupar un puesto específico. Asimismo, la Agencia Sueca de Cooperación para el Desarrollo Internacional (SIDA), ha definido a la corrupción como la obtención de ganancias impropias por parte de instituciones, organizaciones, compañías o individuos por su posición en una operación, causando daños o pérdidas, es decir, el abuso de la

\footnotetext{
${ }^{1}$ La Convención de las Naciones Unidas contra la corrupción es el único instrumento universal anticorrupción legalmente vinculante. Este texto fue negociado durante siete sesiones llevadas a cabo entre el 21 de enero de 2002 y el 1 de octubre de 2003. Cubre cinco áreas principales: medidas preventivas, criminalización y cumplimiento de la ley, cooperación internacional, recuperación de activos; y asistencia técnica e intercambio de información.

${ }^{2}$ Traducción del inglés "The abuse of public office for private gain”. (World Bank) y “The abuse of entrusted power for private gain". (Transparency international)
} 
confianza, poder o posición para beneficios indebidos (SIDA, 2004), (SIDA, 2015). En un sentido más amplio, la corrupción implica la obtención de una utilidad privada propia o para beneficiar a terceras personas, a través de violaciones a las normas legales y sociales, dirigidas en detrimento de los intereses públicos y en perjuicio del bien colectivo.

En el diccionario de Ciencia Política (Nohlen \& Schultze, 2006), la corrupción se define como el abuso del poder público, cargos o nombramientos con el fin de obtener utilidad privada propia y/o para beneficiar a terceras personas a través de violaciones de normas legales y también sociales, que por lo regular se llevan a cabo secretamente, están dirigidas en contra de los intereses públicos y atentan contra el bien común.

Otras definiciones relevantes consideran a este fenómeno como el mal uso de un cargo o función con fines no oficiales y que se gesta en la administración pública, empero, el sector privado participa en la mayoría de los casos de corrupción gubernamental (Klitgaard, 1998); la apropiación de fondos públicos para uso privado y la malversación de fondos públicos por políticos y altos funcionarios que suponen un perjuicio para el desarrollo económico de un país (Gray \& Kaufmann, 1998); como el resultado de la ineficiencia institucional, la inestabilidad política, los trámites burocráticos y la poca solidez de los sistemas legislativos y judiciales (Mauro, 1998).

Se considera además como corrupción la capacidad que tienen los políticos de abusar del poder que se les confía o que han usurpado, para amasar sus propias fortunas y seguir sus objetivos personales en detrimento de los ciudadanos (Acemoglu \& Robinson, 2013); el comportamiento que se desvía de los deberes normales de un servidor público debido a circunstancias privadas, obtención de ganancias pecuniarias o estatus, así como una violación de reglas en contra del ejercicio de ciertos tipos de influencia (Nye, 2002); la institución extra legal utilizada por individuos o grupos para lograr influencia sobre las acciones de la burocracia (Leff, 2002); la existencia de una actitud del responsable de un puesto público, con unas funciones y atribuciones definidas, inducida por cualquier medio, legal o no, a actuar favoreciendo a quien proporciona el beneficio y dañando al público y a sus intereses (Villoria, 2002).

Finalmente, otras otros referentes toman este fenómeno como el uso indirecto del poder público para obtener beneficios privados, convirtiendo la función pública como una fuente de enriquecimiento privado (Bautista, 2005); el abuso de los roles públicos para beneficio privado, en el sentido que el abuso puede ser iniciado por la persona que ocupa el puesto público o por aquellos que buscan ejercer influencia en ellos (Johnston, 1986); el establecimiento de intereses personales sobre aquellos a los que la o el servidor público se comprometió a servir, puede implicar promesas, amenazas, o ambas, al igual que manifestarse como actos de omisión y comisión sobre servicios lícitos o ilícitos dentro o fuera del servicio público (Klitgaard, 1988) y el uso de poder para obtener beneficios personales de cierto tipo, actuando como si las atribuciones propias del ejercicio de ese poder fueran más bien atribuciones particulares (Page, 2018).

Conforme a las definiciones antes citadas, muchas consideran una forma específica de corrupción, como lo es el abuso de autoridad ${ }^{3}$ o el soborno ${ }^{4}$, sin embargo, se toman como válidas debido a que la esencia del fenómeno es la misma, es decir, que la corrupción es el uso del poder o autoridad investida a un servidor público como la vía para obtener beneficios o ganancias indebidas,

\footnotetext{
${ }^{3}$ Las fracciones III, VIII y IX del artículo 212 del Código Penal para el Estado de Tamaulipas prevé como abuso de autoridad el indebido retardo o negativa a los particulares de la protección o servicios que tenga obligación de otorgarles, solicitar sueldos o dádivas a sus subalternos, otorgar empleo, cargos o contratos a personas físicas o morales previo conocimiento de que no se cumplirá la encomienda, entre otros actos.

${ }^{4}$ De acuerdo al Centro de Investigación sobre la Corrupción U4, el soborno se define como el ofrecimiento o intercambio de dinero, servicios u otros valores para influenciar el juicio o conducta de una persona en una posición de poder. Este puede ser de tipo activa (cuando se refiere al acto de prometer o dar el soborno) o pasiva (cuando se trata recibir el soborno).
} 
y que a su vez dicho actuar es impulsado por diversos factores tanto del que acepta el soborno como del que lo promueve.

Della Porta y Vannucci (2005), proporcionan un significado más amplio sobre este fenómeno, identificando elementos esenciales que permiten su mayor entendimiento. Para ellos, en un contexto burocrático, la corrupción implica: a) una violación oculta a un contrato que, de forma implícita o explícita, representan una delegación de responsabilidad y el ejercicio de un poder discrecional; b) por un agente público, quien en contra de los intereses o preferencia del principal c) actúa en favor de un tercero, por el cual recibe una recompensa (pág. 1).

En ese sentido, para reforzar lo argumentado es conveniente citar lo que al respecto refiere el Centro de Investigación U4 sobre la Corrupción (U4, s/f), respecto a la definición de corrupción:

"Todas las variaciones de expertos y especialistas incluyen invariablemente tres elementos comunes: abuso (mal uso, violación) del poder conferido (deber, puesto, etc.) y el beneficio privado. En un lenguaje cotidiano, el término es utilizado de una forma más amplia para denotar una amplia variedad de actos objetables o inmorales, y no solo esos asociados con el deber formal ${ }^{5}$."

Un aspecto que no puede dejarse de lado es que el corrupto, tanto el que propone como el que acepta, se encuentran conscientes de que el acto es ilegal o moralmente incorrecto, empero, el beneficio que se obtiene va más allá del temor a ser sorprendidos o sancionados, aunado al hecho de que estiman que la posibilidad de imposición de un castigo es remota o nula.

Ahora bien, la corrupción se ha vuelto tan común, que es casi normal considerarla como parte de la cultura del país, pues adopta tantas formas y cubre tal variedad de actividades públicas que frecuentemente, se hace difícil reconocerla (Sánchez, 2012), por lo que se ubica como un fenómeno transversal que ha afectado diversos momentos de la cultura humana, además que puede existir en todo tiempo y lugar (Betanzos, 2017); en el sector público, ésta ha influido seriamente en diferentes aspectos de la sociedad, no solo en lo que concierne a los niveles de credibilidad y confianza de la ciudadanía, sino al alto costo que representa para la economía, tanto a nivel federal como de las entidades federativas. Los actos de corrupción se identifican prácticamente en cualquier tipo de trámite y nivel de gobierno, variando en la complejidad de los actos, el grado de beneficio indebido que se obtiene y el tipo de servidores públicos que intervienen en ellos.

Existen diferentes contextos sobre este fenómeno tal y como lo señalan (Solimano, Tanzi, \& Del Solar, 2008), quienes hacen referencia en primer término a la Corrupción del Estado, como aquella que involucra a funcionarios, agencias y organismos del Estado, ya sea a un nivel centralizado (Secretarías), descentralizados (paraestatales, empresas de participación estatal mayoritaria, fideicomisos) u organismos autónomos, y en segundo, la Corrupción política, que concierne a ciertos miembros de partidos políticos que buscan extraer recursos del Estado y explotar posiciones de influencia para fines de financiamiento de partidos o del enriquecimiento personal de ciertos miembros o fundadores de estos.

Ahora bien, la Corrupción en el sector privado, se genera cuando los altos ejecutivos de empresas privadas pueden sacar provecho de información asimétrica - o privilegiada - sobre materias esenciales del funcionamiento de una empresa o de información sobre oportunidades de negocio que debieran ser de carácter público. Otra forma en que este tipo de corrupción se aprecia,

\footnotetext{
5 Traducción de: "Although this is the most common definition, other definitions exist. The World Bank, for example, defines corruption more narrowly as "abuse of public office for private gain". All expert/specialist variations nevertheless include three common elements: abuse (misuse, violation) of entrusted power. (duty, office, etc.) and private benefit. In everyday language, the term is used more broadly to denote a wide variety of objectionable or immoral acts, and not only those associated with formal duty".
} 
es en el momento en que empresas internacionales realizan pagos a agentes locales, funcionarios del estado o influyen en decisiones legislativas para obtener tratamientos fiscales o tributarios favorables.

Finalmente, la Corrupción en el sector no-gubernamental, se puede definir como la utilización indebida de beneficios fiscales, el gozo de deducciones privilegiadas o la obtención de prerrogativas sobre donativos que en circunstancias normales no deberían obtener.

La corrupción puede generarse por causas que pueden ser genéricas, cuando se identifican como el conjunto de aspectos sociales y económicas muy abstractas que parecen favorecer la aparición de la corrupción, y las específicas, que se refieren a ciertas circunstancias que impulsan los actos de corrupción, como lo son salarios de bajo nivel, falta de continuidad de los servidores públicos en sus puestos, ausencia / escasez de sanciones, sobre regulación administrativa, la magnitud económica de las consecuencias de la decisión a tomar, doble lealtad del servidor público, entre otras no menos relevantes (González, 1999).

No solamente se trata de visualizar el acto de corrupción desde la perspectiva del servidor público, aún y cuando puede considerarse que es el único responsable de la existencia de este fenómeno, sin embargo el ciudadano o el usuario también juega un papel importante al momento de que se da tal práctica indebida, es decir, existe una corresponsabilidad del ciudadano en el sentido que puede impulsar o instigar al servidor público a cometer un acto corrupto aprovechándose de la necesidad que pudiese tener el empleado gubernamental.

Es por ello, que la corrupción se puede definir también como un acto bilateral en que concurren por un lado un impulsor de la conducta indebida y por el otro, aquél que lo acepta, aún y con el conocimiento de estar realizando algo indebido, no importando la parte que promueva la conducta, siendo el determinante el servidor público quien posee la facultad o poder otorgado para obtener el beneficio indebido.

En la definición propuesta se identifica una corrupción activa y pasiva, las cuales de acuerdo con el Manual de las Naciones Unidas para medidas de anticorrupción prácticas para los Investigadores y Fiscales6 (ONU, 2004b), se identifica la primera como el acto de ofrecer o pagar un soborno, y la segunda, consiste en solicitar o recibir un soborno; un acto de corrupción puede ser iniciado bajo cualquier modalidad, por una persona que ofrece un soborno o por un servidor público que lo solicita.

Conforme a lo abordado, la corrupción puede manifestarse de diferentes formas, pero todas confluyen en generar un daño o menoscabo en el interés colectivo, pues los recursos que originalmente son destinados a la satisfacción de necesidades de la sociedad son re direccionados para beneficios particulares.

Entre los efectos de la corrupción se ubican especialmente aquellos relacionados con servicios básicos para la ciudadanía, es decir, en materia de salud, se manifiesta en la falta de medicamentos disponibles en los hospitales debido a redes de corrupción que implican a servidores públicos y proveedores, disminuye la cobertura geográfica de salud al inhibir el acceso a los servicios básicos hospitalarios, debilita los recursos públicos destinados al ramo haciéndolos insuficientes, afecta la calidad de la prestación de los servicios al contratar personal pobremente capacitado; en el caso de la impartición de justicia, al momento en que las partes deben entregar dádivas a los juzgadores para impulsar los procedimientos judiciales; en materia de educación, la falta de procedimientos transparentes y la venta de plazas para nuevos maestros o su entrega a personas que no cumplen con el perfil, la manipulación de precios por parte de proveedores de bienes y servicios a efecto de otorgar dádivas a servidores públicos, el cobro de cuotas ilegales; en 
cuestión de obras públicas, al solicitar al contratista un porcentaje del contrato sujeto a licitación, que ocasiona la reducción de la calidad de los materiales utilizados e implica un riesgo para los ciudadanos, sólo por mencionar algunos.

No es óbice el afirmar que el fenómeno de la corrupción afecta de manera negativa la legitimidad de las instituciones que integran la administración pública (federal, estatal o municipal), pues los recursos humanos, materiales y financieros se desvían del cumplimiento de su función principal hacia la satisfacción de intereses particulares, como lo son el enriquecimiento o la perpetuación en el poder.

\section{2.- Los diferentes tipos de corrupción.}

La corrupción en el servicio público puede identificarse de diferentes maneras, partiendo de la tipología formulada por la Convención de las Naciones Unidas contra la Corrupción (United Nations, 2004). Esta Convención ${ }^{6}$, anexa a la resolución 58/4 de la Asamblea General de las Naciones Unidas de data 31 de octubre de 2003, tipifica en su Capítulo III los actos de corrupción más frecuentes en los sectores público y privado.

Los tipos de corrupción que se identifican son el soborno a los funcionarios públicos nacionales (Art. 15), soborno a funcionarios extranjeros y de organizaciones internacionales públicas (Art. 16), malversación o peculado, apropiación indebida u otras formas de desviación de bienes por un funcionario público (Art. 17), tráfico de influencias (Art. 18), abuso de funciones (Art. 19), enriquecimiento ilícito (Art. 20), soborno (Art. 21) y malversación o peculado de bienes en el sector privado (Art. 22), blanqueo del producto del delito (Art. 23), encubrimiento (Art. 24) y obstrucción de la justicia (Art. 25) 7 .

En la legislación mexicana, el Código Penal Federal (DOF, 2020) vigente prevé en su Título Décimo "Delitos por hechos de corrupción" los actos o las acciones llevados a cabo por servidores públicos que encuadran en hechos de corrupción, dicho título comprende de los artículos 212 a 224 y prevé los ilícitos de ejercicio ilícito de servicio público (art. 214), abuso de autoridad (art. 215), coalición de servidores públicos (art. 216), uso ilícito de atribuciones y facultades (art. 217), concusión (art. 218), intimidación (art. 219), ejercicio abusivo de funciones (art. 220), tráfico de influencia (art. 221), cohecho (art. 222), cohecho de servidores públicos extranjeros (art. 222 bis), peculado (art. 223) y enriquecimiento ilícito (art. 224). En el caso de los delitos de hostigamiento sexual y extorsión, éstos se encuentran previstos en los artículos 259 bis y 390 del mismo Código.

Para la codificación punitiva del estado de Tamaulipas (POE, 2020), los delitos por corrupción, se estipulan en su título octavo y comprende los artículos 208 al 231 y prevé los ilícitos de ejercicio ilícito de servicio público (art. 209), abuso de autoridad (art. 212), coalición de servidores públicos (art. 214), cohecho (art. 216), peculado (art. 218), concusión (220), uso ilícito de atribuciones y facultades (art. 222), intimidación (art. 224), ejercicio abusivo de funciones (art. 226), tráfico de influencia (art. 228) y enriquecimiento ilícito (art. 230).

\section{3.- Definiendo la sextorsión}

\footnotetext{
${ }^{6}$ La Convención de las Naciones Unidas contra la corrupción es el único instrumento universal anticorrupción legalmente vinculante. Este texto fue negociado durante siete sesiones llevadas a cabo entre el 21 de enero de 2002 y el 1 de octubre de 2003. Cubre cinco áreas principales: medidas preventivas, criminalización y cumplimiento de la ley, cooperación internacional, recuperación de activos; y asistencia técnica e intercambio de información.

${ }^{7}$ El Capítulo III sobre Penalización y aplicación se integra por los artículos 15 al 42 e incluye no sólo la tipificación de acciones corruptas, sino además lo relativo a la prescripción (art. 29), fallo y sanciones (art. 30), embargo preventivo, incautación y decomiso (art. 31), protección de testigos, peritos y víctimas (art. 32), protección de denunciantes (art. 33), indemnización por daños y prejuicios (art. 35), entre otros.
} 
La sextorsión, de acuerdo a la organización Thorn ${ }^{8}$ se centra en la amenaza de exhibir imágenes sexuales con el objetivo de lograr que una persona haga algo. Estas amenazas provienen tanto de desconocidos que se conocen en internet, como de parejas sentimentales que intentan hostigar, avergonzar y controlar a las víctimas ${ }^{9}$. Sin embargo, con la finalidad de evitar una confusión de términos, resulta necesario dejar en claro que el presente artículo se centra en una modalidad diferente de sextorsión, en la que la pornografía no es la situación central, así como tampoco el uso de las Tecnologías de la Información y Comunicación (TIC's) como medios de difusión o presión por parte del perpetrador.

Establecer una definición de sextorsión aún está en una fase preliminar, sin embargo, la Asociación Internacional de Juezas (IAWJ) ${ }^{10}$, en su documento denominado "Combatiendo la sextorsión. Un estudio comparativo de leyes para perseguir la corrupción que implica la explotación sexual", define a la sextorsión como el "abuso de poder para obtener un beneficio sexual o ventaja. La sextorsión es una forma de corrupción en la que el sexo, en lugar del dinero, es la divisa para el soborno. No está limitado a ciertos países o sectores, pero puede encontrarse dondequiera que haya personas con poder y falta de integridad que intentan explotar sexualmente a aquellas o aquellos quienes son vulnerables y dependen de su poder" (IAWJ, 2015, pág. 19).

En relación a su concepto, la IAWJ identifica tres componentes importantes: 1.- una persona a la que se le ha otorgado poder; 2.- un abuso de autoridad, al ejercerla a cambio de un favor sexual; y 3.- se confía en el poder coercitivo de la autoridad en lugar de una violencia física o la fuerza para obtener el favor sexual (UNODC, 2019). Asimismo, considera que el componente sexual no debe, en el estricto sentido, implicar relaciones sexuales, sino también actos de índole sexual como lo son la exposición de partes íntimas o posar para fotos de naturaleza erótica.

Para Elden, Calvo, Bjarnegard, Lundgren y Jonsson (2020), la sextorsión es una forma de corrupción y violencia de género, que sucede cuando una persona con autoridad abusa de ésta para obtener un favor sexual a cambio de un servicio o beneficio el cual ésta bajo su poder otorgar o negar. Asimismo, consideran que la sextorsión es una conducta corrupta en la cual el sexo es la divisa de cambio y una conducta sexual donde se genera un "beneficio" mutuo, es decir, el perpetrador obtiene un favor sexual y la víctima el servicio requerido, o en su caso, la necesidad satisfecha. La carga de la responsabilidad en este acto recae en el servidor público que abusa de su poder de autoridad a lo que se agrega la vergüenza, temor y falta de denuncia por parte de la víctima, lo que la hace ver como cómplice e impide que se proceda legalmente contra el perpetrador.

El Departamento de Administración y Servicio Público de la República de Sudáfrica, dentro de sus políticas y procedimientos en el manejo de hostigamiento sexual en el servicio público (2013), no obstante que no hace referencia explícita al término sextorsión, en sus puntos 8.4 y 8.5 del apartado 8 "formas de hostigamiento sexual", se prevén conductas que pueden equipararse con el caso a estudio. En el punto 8.4 se establece que existe un favoritismo sexual cuando una persona en una posición de autoridad recompensa únicamente a aquéllas o aquéllos que responden a sus avances sexuales, mientras que los que no aceptan les son negadas promociones, incrementos salariales y otras formas de reconocimiento; por lo que respecta al punto 8.5 , se trata de un hostigamiento de quid pro quo (una cosa por otra), y ocurre cuando un dueño, patrón, supervisor, miembro de la administración o compañero de trabajo busca o intenta influenciar el proceso de

\footnotetext{
${ }^{8}$ Organización creada en 2012 cuyo objetivo es proteger a los niños y niñas de la explotación sexual, a través de tres pilares estratégicos: 1). - acelerar la identificación de víctimas, 2). - equipar las plataformas tecnológicas, y 3). - empoderar al ciudadano

${ }^{9} \mathrm{https}: / / \mathrm{www}$.thorn.org/sextortion/

${ }^{10}$ International Association of Women Judges, por sus siglas en inglés.
} 
contratación, promoción, entrenamiento, disciplina, despido, incremento salarial o de otros beneficios a favor de un empleado o candidato, a cambio de un favor sexual.

Dentro de las conductas identificadas por este departamento que pueden considerarse como hostigamiento (apartado 8.6), destacan la solicitud de favores sexuales a cambio de empleo y de beneficios laborales (8.6.2), solicitudes persistentes para citas y favores sexuales (8.6.12) y cualquier forma de coerción o chantaje para contratación y/o promociones, así como la falta de promoción, despido o detrimentos ocupacionales si la persona se niega (8.6.14).

Otro intento de definir la sextorsión puede ubicarse en Carnegie (2019), quien la ubica como el abuso de autoridad o puesto para explotar a alguien quien es vulnerable o dependiente de su poder, e implica dos componentes, el de corrupción, entendido como la búsqueda de un beneficio personal a cambio del ejercicio del poder otorgado; y el de abuso sexual, que es la solicitud de intervenir en una actividad sexual no deseada o proporcionar un favor sexual.

En ese sentido, al hacer referencia a la sextorsión y conforme a las definiciones anteriores, se pueden ubicar ciertos elementos que son comunes en otras formas de corrupción, como lo son la interacción de dos personas (la que impulsa el acto y la que lo acepta), la búsqueda de un beneficio personal, la violación de normas legales y morales, y principalmente, la presencia de un poder otorgado a una de las partes.

Sin embargo, la sextorsión contiene elementos determinantes que resulta conveniente abordar de acuerdo a lo establecido por Zahiragic et. al. (2011), a saber: 1.- extorsión por sexo u ofrecimientos sexuales en diferentes situaciones (lugar de trabajo, entorno educativo u otras circunstancias) como una forma de configurar delitos; 2.- la forma de pago es a través de servicios sexuales, en sustitución del dinero; 3.- se utiliza una posición jerárquica superior (un jefe, un maestro) o cualquier posición de poder o de servidor público para solicitar servicios sexuales de un subordinado (un empleado, estudiante). Estos autores determinan que la sextorsión no representa un aspecto individual de violación o conducta violenta, pero una forma de soborno, en el que se utilizan servicios sexuales como una forma de pago en lugar del dinero.

Ahora bien, conforme al párrafo que precede, se considera que el tercer elemento deja de lado una situación en la que puede ubicarse la víctima, es decir, se limita a establecer que la sextorsión ocurre en una relación de subordinación entre jefe - empleado, maestro - alumno empero, estos casos pueden darse aun cuando no existe una subordinación, pues se puede tratar de un usuario del servicio público o cualquier ciudadano que no guarda esa relación con el perpetrador, por lo que no se cumpliría el supuesto de enmarcar esa relación jerárquica como determinante de la sextorsión.

Es por ello que se propone una definición de la sextorsión como aquel acto de corrupción en que una persona a quien la ley le confiere un poder de decisión, lo usa para obtener un beneficio indebido que se traduce en favores sexuales en perjuicio de otra persona, independientemente que exista o no una relación de subordinación entre el perpetrador y la víctima.

La sextorsión, entonces, puede implicar una combinación de dos actos de corrupción, como lo son el abuso de funciones (pues se trata de la realización u omisión de un acto por parte de un funcionario público en el ejercicio de sus funciones, en franca violación a lo estipulado en la ley, con el fin de obtener un beneficio indebido para sí mismo o para otra persona o entidad) y el soborno de funcionarios (por tratarse de la solicitud o el ofrecimiento de un beneficio indebido a cambio de un provecho para las partes implicadas). Por ello, para que suceda la sextorsión, el perpetrador de este acto, debe contar con una característica sine qua non, que es la de contar con 
autoridad para tomar ventaja de su puesto para obtener provecho de la víctima a cambio de empleo (aspecto laboral), calificaciones (educación), consultas médicas (salud) o cualquier tipo de trámite.

De acuerdo al estudio llevado a cabo por la Asociación Internacional de Juezas (IAWJ, 2015) titulado "Combatiendo la sextorsión: un estudio comparativo de leyes para perseguir la corrupción que concierne la explotación sexual", para que se configure la sextorsión deben identificarse dos conductas:

1.- Actividad sexual. - Contempla una solicitud implícita o explícita de llevar a cabo cualquier tipo de actividad sexual no deseada, que puede ir desde relaciones sexuales o a exponer partes del cuerpo.

2.- Corrupción. - Las personas que demandan la actividad sexual deben ocupar una posición de autoridad, mediante la cual abusan para convencer en la aceptación de un acto sexual a cambio de ejercer el poder que se les ha otorgado, es decir, el que lleva a cabo el acto aplican su autoridad para su beneficio propio.

En la literatura se pueden identificar situaciones relacionadas con la sextorsión, Mumporeze, Han-Jin, \& Nduhura (2019) hacen referencia a diversos actos en varios países, como lo son Estados Unidos de Norteamérica, donde gerentes solicitaban favores sexuales a cambio de promociones laborales; denuncias de mujeres migrantes de Irak y Siria a quienes eran víctimas de sextorsión en su trayecto, inclusive en territorio europeo; en los países africanos, donde a las estudiantes se eran obligadas a tener sexo con sus profesores a cambio de calificaciones, al igual que Reimer (2011) que efectúa un recuento de situaciones en diversas partes del mundo donde se realizaron actos de sextorsión.

Asimismo, Kyria (2019) y Yusuph (2016) identifican que, en el caso de las Universidades, los actos relacionados con hostigamiento, en mayor medida de alumnas, es un serio problema en la educación superior, pero que no es ampliamente estudiado o reconocido, que a su vez es impulsado por la carga burocrática que representan los trámites escolares, tales como inscripciones, titulación, becas, etcétera.

Para comprender la diversidad de situaciones en que pueden darse casos de sextorsión, Transparencia Internacional, en el reporte denominado "Rompiendo el silencio sobre la sextorsión: la relación entre poder, sexo y corrupción" (2020) se hace mención que este fenómeno se ha identificado en los procesos de migración (durante la travesía y la llegada al destino), en estas situaciones las mujeres son continuamente vulnerables; en los procesos judiciales se han documentado casos en que los jueces a cargo de juicios solicitan favores sexuales a fin de dictar sentencias favorables; concerniente a la interacción con elementos policíacos, la sextorsión se da de forma constante, lo que genera un limitado acceso a la justicia para las víctimas y suprime la aplicación de la ley; dentro de las instituciones públicas, ocurre frecuentemente en el contexto de la toma de decisiones atinentes a la contratación y la promoción en el empleo, cuando servidores públicos con posiciones de poder solicitan sexo de candidatos o subordinados a cambio de decisiones favorables; los campos de refugiados ofrecen una amplia probabilidad de ocurrencia de sextorsión, donde la población es altamente dependiente de ayuda para su supervivencia básica; finalmente, en el acceso a los servicios básicos, esta conducta se identifica, en el momento en que las mujeres necesitan el acceso a la provisión de agua y alimentos. 


\section{4.- Sextorsión, extorsión y hostigamiento sexual}

Para el caso del hostigamiento sexual, éste se configura cuando una persona, con fines lascivos asedie reiteradamente a otra persona de cualquier sexo, valiéndose de su posición jerárquica derivada de sus relaciones laborales, docentes, domésticas o cualquiera otra que implique subordinación, mientras que en el caso de a extorsión, ocurre cuando una persona, sin tener derecho a ello, obligue a otro a dar, hacer, dejar de hacer o tolerar algo, obteniendo un lucro para sí o para otro o causando a alguien un perjuicio patrimonial.

Ahora bien, para diferenciar la sextorsión del hostigamiento sexual, de acuerdo a Steel y Lee (2007:131), citados por Hlongwane (2017), éste se define como avances sexuales no deseados, solicitud de favores sexuales u otras conductas verbales o físicas de naturaleza sexual, las cuales ocurren cuando: a) existe una sumisión implícita o explícita en el contexto de una relación laboral, b) la sumisión o el rechazo a esa conducta influye en las decisiones del empleador que afectan al individuo, y c) tal conducta tiene el propósito o efecto de interferir con el desempeño del trabajo de un individuo, o para crear un ambiente de trabajo hostil, intimidante $\mathrm{u}$ ofensivo.

Transparencia Internacional efectúa una distinción de lo que no debe considerarse como extorsión sexual (sextorsión), en el sentido de que no es el término adecuado para describir una violencia sexual o de género que realiza un perpetrador que no está investido con un poder en relación con la víctima, por ejemplo, la violencia doméstica; insinuaciones sexuales que no son propiamente compensadas con una transacción no sexual, por ejemplo el hostigamiento sexual en el transporte público; actividad sexual que es obtenida a través del uso o amenaza de infringir fuerza física (aun cuando la persona que lo realiza cuenta con un poder conferido), como por ejemplo la violación (Transparency international, 2017).

Ramsaroop y Parumasur (2007) argumentan que las víctimas de hostigamiento sexual experimentan una amplia gama de reacciones emocionales, tales como la humillación, falta de auto estima, sentimientos de culpa, pérdida de la confianza, ira y depresión, en ese mismo sentido, Mumporeze y Nduhura (2019) identifican una serie de consecuencias individuales y colectivas de la sextorsión, tales como efectos psicológicos negativos, ansiedad, depresión, vergüenza y desconfianza, así como una reducción en la calidad y cantidad de la capacidad de trabajo, falta de satisfacción laboral y abstencionismo, afectación a la autoestima y hasta el suicidio; a nivel colectivo, este tipo de actos pueden traducirse en costosos litigios a cargo de las instituciones, el decremento de la productividad de los empleados, entre otras, lo que implica que la sextorsión no es sólo una forma diferente de corrupción, sino también otra forma de violencia sexual que empequeñece y degrada a las víctimas (Hlongwane, 2017).

El Código Penal de Tamaulipas (POE, 2020) contempla los ilícitos de hostigamiento sexual, acoso sexual y extorsión, los cuales se encuentran previstos en los preceptos 276 bis. 276 ter y 426 , respectivamente, configurándose el primero como el acto que realiza una persona quién valiéndose de una posición jerárquica derivada de la relación laboral, docente, doméstica o cualquiera otra que genere subordinación, asedie a otra persona, emitiéndole propuestas, utilizando lenguaje lascivo con este fin o le solicite ejecutar cualquier acto de naturaleza sexual; el segundo como las conductas verbales o físicas o ambas realizadas por una persona hacia otra con quien no guarda una relación de subordinación, relacionadas con la sexualidad que la pongan en riesgo o la dejen en estado de indefensión. En el caso de la extorsión, se da cuando una persona sin derecho, por cualquier medio, obliga a otra a dar, hacer, tolerar o dejar de hacer algo, con ánimo de lucro, o con la intención de obtener un beneficio, cualquiera que este sea, u obteniéndolo para sí o para otro o causando un perjuicio patrimonial, moral o psicológico, a la identidad profesional o la imagen profesional, en contra de una persona o personas. 
La forma más sencilla en que puede entender la diferencia sextorsión - extorsión hostigamiento sexual - en los términos de la codificación penal del estado de Tamaulipas - radica en que no es necesario que exista una subordinación entre el perpetrador y la víctima, pues como ha quedado de manifiesto, la parte afectada puede tener una relación laboral o también requerir del servicio de la persona con autoridad (lo que solamente se da en la sextorsión); la falta de amenazas de violencia o agresión física si la víctima no cumple con lo que se le solicita (como sí sucede con la extorsión) y la existencia del elemento quid pro quo (una cosa por otra) en que la víctima recibe un beneficio a cambio de aceptar las solicitudes sexuales del perpetrador o viceversa (lo que no ocurre en el hostigamiento). Al no tener la sextorsión del componente de la violencia o fuerza física, normalmente se deja de lado como un tipo de abuso sexual (Hendry, 2020).

\section{5.- La sextorsión en la legislación mexicana.}

Recientemente en México el tema de la sextorsión ha sido abordado en las iniciativas de reforma a los códigos penales tanto Federal como de las entidades federativas como un delito de ciberacoso, que se configura al utilizar las Tecnologías de la Información y Comunicación (TIC's), como lo son las redes sociales (facebook, twitter, instagram), mensajerías instantáneas (whatsapp, telegram), correo electrónico o cualquier otro medio digital para afectar la tranquilidad de la persona con mensajes de texto, videos, impresiones, gráficas o fotografías, a fin de obtener un beneficio indebido, lucro o simplemente ocasionar un daño o menoscabo en la dignidad personal.

La I Legislatura de la Ciudad de México, presentó el 12 de septiembre de 2019 una iniciativa de reforma del Capítulo III del Código Penal del Distrito Federal, para incluir la violencia digital $^{11}$ como delito, al igual que hace mención de la sextorsión como una conducta desplegada por una persona con la finalidad de amenazar a otra con la publicación de un contenido de índole sexual a cambio de un nuevo intercambio sexual o económico, reciba o condicione a cambio de cualquier beneficio de la publicación de este contenido (Congreso de la Ciudad de México, 2019).

En el estado de Chihuahua, el 8 de octubre de 2019, el partido revolucionario institucional, presentó una iniciativa de adición del artículo 180 bis y de la fracción XI al artículo 204 bis al Código Penal de esa entidad federativa, en la exposición de motivos se contempla la sextorsión como un chantaje en el cual el extorsionador utiliza imágenes sexuales o videos de una persona, que actualmente le ha compartido a través de sexting, para obtener favores sexuales o de carácter económico (Gaytán, 2019).

Dentro de las iniciativas de reforma a las codificaciones penales en donde se ha previsto la sextorsión, se encuentra la del grupo parlamentario del partido del Trabajo, misma que se presentó el 27 de abril de 2020 sobre un proyecto de decreto de adición al artículo 260 del Código Penal Federal, dirigido a la protección de menores de edad y considerando la sextorsión como la difusión de imágenes personales de índole sexual con la intención de un beneficio económico o sexual (Maceda, 2020). El 19 de noviembre de 2018, el grupo parlamentario del Partido Verde, presentó una iniciativa de adición de un artículo 149 ter. del Código Penal Federal, sobre los delitos contra la dignidad de las personas y contempla la sextorsión como el chantaje bajo la amenaza de publicar material sensible en posesión del sujeto activo (poderedomex.com, 2018).

En un sentido similar, la Comisión de Justicia de la LXVI Legislatura del Congreso del Estado de Chihuahua presentó el 20 de octubre de 2020, diversas iniciativas para tipificar el "grooming", el "sexting", la violencia digital y el ciberacoso como delitos dentro del Código Penal de esa entidad federativa. Dentro de la iniciativa, se hace mención de la sextorsión y la definen

\footnotetext{
${ }^{11}$ La misma iniciativa contempla una definición de violencia digital, entendiéndose ésta como cualquier acto que se presenta a través de las Tecnologías de la información y la Comunicación (TlC's), plataformas de redes sociales o correo electrónico, que les cause daño o sufrimiento psicológico, físico, económico o sexual.
} 
como un "tipo de chantaje en el cual el extorsionador utiliza imágenes sexuales o videos de una persona, que anteriormente las ha compartido a través de internet mediante sexting. El objetivo del extorsionador a cambio, es obtener favores sexuales o de carácter económico" (Comisión de Justicia de la LXVI Legislatura H. Congreso del Estado de Chihuahua, 2020).

En lo que respecta a Tamaulipas, el 15 de septiembre de 2020 se aprobó el Decreto mediante el cual se adicionan, entre otros preceptos, el artículo 276 septies correspondiente al delito de violación a la intimidad; y el artículo 390 ter que dispone el ilícito de ciberacoso; ambos del Código Penal del estado. Si bien dentro de la iniciativa de reforma se menciona a la sextorsión como una consecuencia del ciberacoso, de una interpretación armónica de ambos preceptos se contempla como un delito la difusión, publicación o exhibición de imágenes, audio o video de contenido íntimo, erótico o sexual sin consentimiento a través de la utilización de las Tecnologías de la Información y Comunicación (TIC's) con la finalidad de causar daño a la dignidad personal o afecte la paz, la tranquilidad o la seguridad de las personas (Congreso del Estado Libre y Soberano de Tamaulipas, 2019).

Un caso que sobresale es el del estado de Hidalgo, el 19 de marzo de 2019 integrantes de la Sexagésima cuarta Legislatura del Congreso de esa entidad presentaron la iniciativa de reforma del artículo 188 de su Código Penal, mismo que prevé el delito de "aprovechamiento sexual", como aquél que realiza una persona quien aprovechándose de la necesidad de alguien obtenga de éste o de un tercero vinculado a él, la cópula para sí o para otro, como condición para el ingreso o la conservación del trabajo, la promoción de éste o la asignación de aumento, de remuneración o prestaciones para el solicitante, el trabajador o sus familiares (Congreso del Estado Libre y Soberano de Hidalgo, 2019).

El caso del estado de Hidalgo, puede considerarse como el mayor acercamiento a la sextorsión, sin embargo, carece de un elemento esencial, como lo es que la persona que realiza el acto sea un servidor público que cuenta con poder de decisión. Empero, se toma como un avance en el contexto en que se analiza en el presente documento, pues como se advierte de las iniciativas antes citadas, hasta ahora la sextorsión se ha relacionado con la difusión, exhibición o publicación de material de contenido sexual con la finalidad de denigrar o afectar psicológicamente a otra persona, e inclusive para obtener un beneficio económico y no como un medio de abuso de poder para generar beneficios particulares.

\section{PROCEDIMENTO METODOLÓGICO}

Para el desarrollo del presente artículo se realizó una revisión bibliográfica de fuentes secundarias constituidas por los informes emitidos por Transparencia Internacional y la Asociación Internacional de Juezas (IAWJ), además de estudios teóricos y empíricos al respecto del tema de la sextorsión.

La primera parte de la revisión bibliográfica se enfocó en exponer las diversas conceptualizaciones que existen en torno al término de corrupción, esto, con la intención de proponer a partir de dichas posturas un argumento que defina el término de corrupción que se considerará como fundamento en el presente artículo y que sirve como punto de partida para el entendimiento de la sextorsión.

A partir de la contextualización anterior y con la finalidad de integrar la parte teórica que exponga los estudios realizados en torno al tema de sextorsión, se realizó una búsqueda en diversas bases de datos, tales como Transparencia Internacional (TI), Redalyc, Researchgate, Academia, entre otros. Se obtuvieron aproximadamente 25 artículos y documentos de investigación que a partir de un análisis permitieron construir el estado del arte sobre la sextorsión. Por último, se analizaron 
codificaciones tanto a nivel federal como estatal, para con ello, visualizar la forma en que actualmente el fenómeno de la sextorsión se aborda en la legislación mexicana, lo que permitió identificar hasta donde estos documentos jurídicos consideran esta nueva forma de corrupción en México.

\section{CONCLUSIONES}

Conforme al análisis de las iniciativas de reforma a las diversas codificaciones penales en el país que se abordaron en el presente artículo, la sextorsión se ha relacionado exclusivamente con la difusión de imágenes y videos de contenido sexual o erótico con la intención de denigrar, perjudicar o afectar la dignidad de una persona. Dicha relación se ha fortalecido con la integración de la llamada "Ley Olimpia" a las diversas legislaciones de los estados derivado de la experiencia real de una mujer que sufrió acoso en redes sociales por la distribución de material de esa naturaleza. Estas reformas significan un avance en el aspecto de reconocer variantes en la determinación de nuevas violencias basadas en género, que, si bien afectan en mayor medida a las mujeres, también puede ser dirigida a hombres.

En el desarrollo del presente artículo se deja entrever que el fenómeno de la sextorsión va más allá que la difusión de imágenes o videos de contenido sexual, sino que interviene un elemento adicional que proporciona una modalidad diferente de la sextorsión, pero cuyos efectos negativos son similares o peores, a saber, el uso del poder que es conferido a una persona para obtener beneficios indebidos, que este caso se trata de índole sexual. Esta variante hace que en este contexto la sextorsión se aparte de ser un delito de naturaleza meramente sexual, a ser una modalidad de corrupción que no considera solamente el carácter de subordinación de la víctima por motivos laborales o educativos, sino también los casos en que la o el afectado no guarde relación alguna con el servidor público, más que una dependencia o necesidad del poder de decisión que únicamente el servidor público con poder puede otorgar.

Las consecuencias que se identificaron en esta modalidad de sextorsión se dispersan debido al temor a las represalias que pueden derivarse de la denuncia, aunado al desconocimiento sobre los actos que se pueden equiparar como de este tipo, lo que al mismo tiempo impide que se puedan establecer mecanismos adecuados que permitan identificar este fenómeno y, por ende, mejorar la capacidad de respuesta de las autoridades.

La sextorsión, vista como una modalidad de corrupción, no es un fenómeno de reciente aparición, pues se contemplan un número importante de casos alrededor del mundo en que se ubican los elementos de poder, abuso de autoridad, un favor sexual, y la coacción, sin embargo, las administraciones públicas no han abordado dentro de sus políticas acciones o estrategias tendientes a identificarla, tratarla y evitar su incidencia, así tampoco, se han efectuado estudios empíricos o investigaciones sobre la situación que impera en México (adicional al Barómetro latinoamericano presentado por Transparencia Internacional) y mucho menos en Tamaulipas, que permitan establecer el grado en que este fenómeno se suscita en el estado.

De acuerdo a la IAWJ, los actos de sextorsión en México se impulsan por varios factores, siendo éstos la falta de percepción por parte de la sociedad y de las autoridades; la nula denuncia de las víctimas (debido a la carga psicológica, humillación o escarnio público); la impunidad e inadecuada aplicación de la ley, inclusive su aplicación selectiva y proteccionismo; la falta de transparencia en los procesos judiciales; y, principalmente la corrupción en las instituciones encargadas de dar seguimiento a estos actos, si a esto se adiciona un inadecuado abordaje legal, el problema se maximiza, pues en México la sextorsión se ha limitado al aspecto de la difusión de imágenes y videos a través de las Tecnologías de Información y Comunicación. 
No obstante, se han dado los primeros pasos de regulación de este tipo de actos en el mundo. La ley principal que regula la anticorrupción y el soborno en Tanzania, que es el Acta para la prevención y combate a la corrupción, 2007 (PCCA), la cual se aplica en conjunto de otras leyes relacionadas, como lo es el Acta contra el lavado de dinero, 2006, el acta de control del crimen organizado [Cap 20 R.E 2002], entre otras, contempla en su numeral 25, la sextorsión como una ofensa llevada a cabo por una persona en una posición de poder, quien, en ejercicio de su autoridad, demanda o impone favores sexuales o de cualquier otra índole como una condición para dar empleo, una promoción, un derecho, un privilegio o un trato preferencial ${ }^{12}$ (The United Republic of Tanzania, 2007).

En Bosnia - Herzegovina, el artículo 205 del Código Criminal de la Federación estipula que se comete el delito de relaciones sexuales por abuso de posición, quien induzca a relaciones sexuales o actos equivalentes a otra persona dependiente de una posición en relación a él, debido a circunstancias financieras, familiares, sociales, de salud o cualquier otra condición o circunstancia restringida ${ }^{13}$ (Official Gazette of the $\mathrm{FBiH} 36 / 03,28$ ).

Estos dos ejemplos demuestran que el contemplar esta modalidad de sextorsión, en el sentido de la corrupción, dentro de las legislaciones no es imposible, sino que requiere un abordaje jurídico muy preciso a efecto de facilitar a los encargados de impartir justicia el procesamiento y castigo de este delito. Asimismo, deben establecerse estrategias y programas tendientes a reforzar los valores éticos dentro de las instituciones públicas con perspectiva de género.

Este documento pretende impulsar la cobertura de este tema desde la perspectiva académica, ya que únicamente se basó en la revisión de literatura dejando de lado el incluir las experiencias de personas que han sido víctimas de sextorsión. La principal limitante que se pudo identificar radicó en la falta de literatura especializada sobre el tema en México, al igual que la carencia de bases de datos o estadísticas, tanto oficiales, como de organizaciones de la sociedad civil que pudieran servir de base para establecer la gravedad de este fenómeno en México.

Aún y cuando este tema pueda ser considerado con un alto grado de sensibilidad, es esencial que en proyectos de investigación futuros se contemple la participación de las personas y así establecer las pautas para la formación de políticas públicas y estrategias para combatir esta problemática, al igual que el establecimiento de metodologías e instrumentos de recolección de datos que permitan conocer su incidencia en ciertos contextos, es decir, en la administración pública, sector educativo y salud.

Los primeros pasos para abordar este fenómeno están dados, lo importante es dar el seguimiento y conocer diversos puntos de vista que permitan generar información suficiente para reducir la incidencia de un fenómeno que denigra, humilla y marca a las víctimas, al igual que afecta la capacidad del estado para reaccionar ante esta situación.

\section{REFERENCIAS}

Acemoglu, D., \& Robinson, J. (2013). Por qué fracasan los países. Los orígenes del poder, la prosperidad y la pobreza. México: Paidós.

\footnotetext{
${ }^{12}$ Any person being in a position of power or authority, who in the exercise of his authority, demands or imposes sexual favours or any other favour on any person as a condition for giving employment, a promotion, a right, a privilege or any preferential treatment, commits an offence and shall be liable on conviction to a fine not exceeding five million shillings or to imprisonment for a term not exceeding three years or to both.

13 Article 205. Sexual Intercourse by Abuse of Position (1) Whoever, by abusing his position, induces into sexual intercourse or equivalent sexual act a person who is in a dependent position in relation to him due to the person's financial, family, social, health or other condition or straitened circumstances ...
} 
Bautista, O. (2005). La ética y la corrupción en la política y la administración pública. Tesis. Madrid: UCM.

Betanzos, E. (2017). Reforma en materia de combate a la corrupción. Ciudad de México: Fondo de Cultura Económica.

Carnegie, S. (2019). Sextortion: a crime of corruption and sexual explotation. London: The International Bar Association.

Comisión de Justicia de la LXVI Legislatura H. Congreso del Estado de Chihuahua. (20 de octubre de 2020). Decreto de reforma del Título Quinto del Capítulo VII para denominarlo Contra la Intimidad Sexual; se adicionan al artículo 180 bis un tercer párrafo y un artículo 184 bis del Código Penal del Estado de Chihuahua. Chihuahua, Chihuahua, México.

Congreso de la Ciudad de México. (12 de septiembre de 2019). INICIATIVA CON PROYECTO DE DECRETO POR EL QUE SE REFORMA EL NOMBRE DEL CAPÍTULO III "ACOSO SEXUAL", DEL TÍTULO QUINTO, DEL LIBRO SEGUNDO PARTE ESPECIAL, Y SE ADICIONA UN ARTÍCULO 179 BIS AL CÓDIGO PENAL DEL DISTRITO FEDERAL; Y SE ADICIONA UNA FRACCIÓN VI AL ARTÍCULO 7 DE LA LEY DE ACCESO DE LAS MUJERES A UNA VIDA LIBRE DE VIOLENCIA DE LA CIUDAD DE MÉXICO. Iniciativa con proyecto de Decreto. Ciudad de México, México. Obtenido de https://congresocdmx.gob.mx/archivos/parlamentarios/IN_215_10_12_09_2019.pdf

Congreso de la Ciudad de México. (2020). Código Penal para el Distrito Federal. Recuperado el febrero de 2021, de Gaceta oficial de la Ciudad de México: http://www.paot.org.mx/centro/codigos/df/pdf/2020/COD_PENAL_DF_08_01_2020.pdf

Congreso del Estado Libre y Soberano de Hidalgo. (19 de marzo de 2019). Iniciativa con proyecto de Decreto por el que reforma el artículo 188 y 190; se adiciona el artículo 189 ter y Capítulo V bis al Título V del Código Penal para el estado de Hidalgo. Pachuca, Hidalgo, México.

Congreso del Estado Libre y Soberano de Tamaulipas. (15 de septiembre de 2019). DECRETO MEDIANTE EL CUAL SE ADICIONAN EL CAPITULO IV BIS DENOMINADO "VIOLACIÓN A LA INTIMIDAD” AL TÍTULO DUODÉCIMO DEL LIBRO SEGUNDO; ASÍ COMO EL ARTÍCULO 276 SEPTIES; UN PÁRRAFO TERCERO, RECORRIENDO EL SUBSECUENTE, AL ARTÍCULO 306; EL CAPÍTULO I TER DENOMINADO "CIBERACOSO" AL TITULO DÉCIMO OCTAVO DEL LIBRO SEGUNDO; Y EL ARTICULO 390 TER, AL CODIGO PENAL PARA EL ESTADO DE TAMAULIPAS. Ciudad Victoria, Tamaulipas, México.

Della Porta, D., \& Vannucci, A. (2005). International Conference on Corruption control in Political Life and the Quality of Democracy: A Comparative Perspective Europe - Latin America. Corruption as a normative system.

Department of Public Service and Administration Republic of South Africa. (2013). Policy and procedures on the management of sexual harassment in the public service. Pretoria, South Africa.

DOF. (2020). Código Penal Federal. Recuperado el febrero de 2021, de Cámara de Diputados: http://www.diputados.gob.mx/LeyesBiblio/pdf/9_010720.pdf

Dzhumashev, R. (2014). Corruption and growth: The role of governance, public spending, and economic development. Economic modeling, 37(1), 202-215.

Eldén, A., Calvo, D., Bjarnegard, Lundgren, S., \& Jonsson, S. (2020). Sextortion: corruption and gender-based violence. Stockholm, Sweden: the Expert Group for Aid Studies (EBA).

Gaytán, R. (08 de octubre de 2019). Iniciativa con carácter de decreto. A fin de adicionar un tercer párrafo al artículo 180 bis, y adicionar la fracción XI al artículo 204 bis, del Código Penal del Estado de Chihuahua, a efecto de agravar el delito de sexting cuando exista extorsión., 6. Chihuahua, Chihuahua, México: Congreso del Estado de Chihuahua. Recuperado el 16 de febrero de 2021, de http://www.congresochihuahua2.gob.mx/biblioteca/iniciativas/archivosIniciativas/12923.pdf

Ghalwash, T. (2014). Corruption and Economic Growth: Evidence from Egypt. Modern Economy, I(5), $1001-1009$.

González, J. (Abril de 1999). Corrupción, democracia y responsabilidad política. Isonomía : Revista de Teoría y Filosofía del Derecho(10), 6-24. Obtenido de \{http://www.cervantesvirtual.com/nd/ark:/59851/bmcr2198

Gray, C., \& Kaufmann, D. (marzo de 1998). Corrupción y desarrollo. Finanzas \& desarrollo, 7-10. Recuperado el 9 de febrero de 2021

Habibov, N., Afandi, E., \& Cheung, A. (2017). Sand or grease? Corruption-institutional trust nexus in post-Soviet countries. Journal of Eurasian Studies, 8(2), 172-184.

Hendry, N. (10 de marzo de 2020). Noticing and Combating Sextortion: An Interview with Nancy Hendry. (A. Bertram, Entrevistador) Recuperado el 17 de febrero de 2021 , de https://www.europenowjournal.org/2020/03/09/noticing-and-combating-sextortion-an-interview-with-nancyhendry/

Hlongwane, P. (2017). Sextortion in South African Public Sector Institutions. an ethical and moral dilemma. Administratio publica, 25(2), 7-25. Recuperado el 17 de febrero de 2021

IAWJ. (2015). Combating sextortion: a comparative study of laws to prosecute corruption involving sexual exploitation. Thomson Reuters Foundation.

Johnston, M. (1986). The Political Consequences of Corruption: A Reassessment. Comparative Politics, 18(4), 459477.

Klitgaard, R. (1988). Controling corruption. Los Angeles: University of California.

Klitgaard, R. (1998). La cooperación internacional contra la corrupción. Finanzas \& Desarrollo, 3-6. 
Kyria, M. (2019). Corruption in universities: Paths to integrity in the higher education subsector. U4 anticorruption resource center, 1-32.

Leff, N. (2002). Economie development through bureaucratic corruption. En A. Heidenheimer, \& M. Johnston, Political corruption. Nueva York: Routledge.

Maceda, N. (27 de abril de 2020). Gaceta diputados. Recuperado el febrero de 2021, de INICIATIVA CON PROYECTO DE DECRETO POR EL QUE SE ADICIONA UN PÁRRAFO AL ARTÍCULO 260 DEL CÓDIGO PENAL FEDERAL, A CARGO DE LA DIPUTADA NELLY MACEDA CARRERA DEL GRUPO PARLAMENTARIO DEL PARTIDO DEL TRABAJO: http://gaceta.diputados.gob.mx/PDF/64/2020/abr/INIS-28-ABR/Ini-PT-6.pdf

Mauro, P. (marzo de 1998). La corrupción: causas, consecuencias y un programa para intensificar la investigación. Finanzas \& desarrollo, 11-14. Recuperado el 9 de febrero de 2021

Mumporeze, N., \& Nduhura, D. (2019). Let's spend a night together; i will increase your salary: an analysis of sextortion phenomenon in Rwandan society. Journal of sexual aggression, 1-40. doi:10.1080/13552600.2019.1692920

Mumporeze, N., Han-Jin, E., \& Nduhura, D. (diciembre de 2019). Let's Spend a Night Together; I Will Increase your Salary: An Analysis of Sextortion Phenomenon in Rwandan Society. Journal of Sexual Aggression, 1-40.

Nye, J. (2002). Corruption and development: a cost - benefit analysis. En A. Heidenheimer, \& M. Johnston, Political Corruption. Nueva York: Routledge.

Official Gazette of the FBiH 36/03. (2018 de junio de 28). Bosnia and Herzegovina: Criminal Code of the Federation of Bosnia and Herzegovina. Recuperado el 22 de febrero de 2022, de https://www.refworld.org/docid/5b349a864.html

ONU. (Septiembre de 2004b). United Nations Handbook on Practical Anti-corruption Measures for Prosecutors and $\begin{array}{llllllll}\text { Investigators. } & \text { Recuperado } & \text { el } & 7 & \text { de } & \text { Octubre } & \text { de } & 2020,\end{array}$ https://www.unodc.org/pdf/crime/corruption/Handbook.pdf

ONU. (diciembre de 2008). United Nations Development Program. Recuperado el febrero de 2021, de Corruption and Development: A primer: https://www.undp.org/content/undp/en/home/librarypage/democraticgovernance/anti-corruption/corruption.html

Page, O. (2018). Corrupción institucional. Veritas. Revista de Filosofía y Teología(41), 9-19. Recuperado el 10 de febrero de 2021, de https://www.redalyc.org/articulo.oa?id=2911/291157943001

poderedomex.com. (19 de noviembre de 2018). PIDE COUTTOLENC SANCIONAR LA "SEXTORSIÓN" Y LA “PORNOVENGANZA". Recuperado el febrero de 2021, de http://webcache.googleusercontent.com/search?q=cache:Pzcl3BAz4HoJ:poderedomex.com/pide-couttolencsancionar-la-sextorsion-y-la-pornovenganza/ $\& \mathrm{~cd}=10 \& \mathrm{hl}=\mathrm{es} \& \mathrm{ct}=\mathrm{clnk} \& \mathrm{gl}=\mathrm{mx} \& \mathrm{client}=\mathrm{safari}$

POE. (2020). Congreso del Estado de Tamaulipas. Recuperado el febrero de 2021, de Código Penal para el Estado de Tamaulipas:

https://www.congresotamaulipas.gob.mx/LegislacionEstatal/LegislacionVigente/VerCodigo.asp?IdCodigo=10 2

Ramsaroop, A., \& Parumasur, S. (2007). The prevalence and nature of sexual harassment in the workplace: A model for early identification and effective management thereof. SA Journal of Industrial Psychology. SA Journal of Industrial Psychology, 25-33. Recuperado el 17 de febrero de 2021, de file://C:/Users/ELCOLTAM04/Downloads/367.pdf

Reimer, J. (23 de febrero de 2011). Rights 4 women. Recuperado el 17 de febrero de 2021, de SEXTORTION: Unmasking Hidden Corruption: https://rights4women.wordpress.com/2011/02/23/sextortion-by-johannahreimer/

Sánchez, J. (2012). La corrupción administrativa en México. Estado de México: Instituto de Administración Pública del Estado de México, A.C.

SIDA. (2004). Sida's Anticorruption Regulation. Suecia: Swedish International Development Cooperation Agency. $\begin{array}{lllllll}\text { Recuperado } & \text { el } & 9 & \text { de } & \text { febrero } & \text { de } & 2021,\end{array}$ https://publikationer.sida.se/contentassets/c79a6efb9b324d798e313e404f5f744e/sidas-anticorruptionregulation_1415.pdf

SIDA. (marzo de 2015). Swidish International Development Cooperation Agency. Recuperado el 9 de febrero de 2021, de Gender and Corruption: https://publikationer.sida.se/English/publications/159390/gender-and-corruption/

Solimano, A., Tanzi, V., \& Del Solar, F. (2008). Las termitas del Estado. Ensayos sobre corrupción, transparencia y desarrollo. Chile: Fondo de Cultura Económica.

T.I. (abril de 2020). Transparencia internacional. Recuperado el febrero de 2021, de Breaking the silence around sextortion: the links between power, sex and corruption: https://www.transparency.org/en/publications/breaking-the-silence-around-sextortion

The United Republic of Tanzania. (22 de junio de 2007). Ministry of Finance and Planning Financial Inteligence Unit. Recuperado el 22 de febrero de 2021, de THE PREVENTION AND COMBATING OF OF CORRUPTION ACT, 2007: https://www.fiu.go.tz/pcca.pdf

Transparency International. (2009). The Anti-Corruption Plain Language Guide. Berlin, Alemania: Transparency international. Recuperado el 5 de octubre de 2020 , de https://images.transparencycdn.org/images/2009_TIPlainLanguageGuide_EN.pdf 
Transparency international. (2014). Gender, equality and corruption: what are the linkages? Berlin: Transparency international. Recuperado el 18 de febrero de 2021

Transparency international. (2017). Gender responsive work on land and corruption. Berlin, Alemania: Transparency international. Recuperado el 22 de febrero de 2021 de https://www.wocan.org/sites/default/files/2017_landandcorruptiongenderguide_web.pdf

Transparency International. (2019). Global corruption barometer latin america \& the caribbean 2019 Citizen's views and experiences of corruption. Berlin: Transparencia Internacional. Recuperado el 16 de febrero de 2021, de https://images.transparencycdn.org/images/2019_GCB_LatinAmerica_Caribbean_Full_Report_200409_09142 8.pdf

U4 Anti-corruption Resource Centre. (s.f.). Glossary. Recuperado el 5 de octubre de 2020, de https://www.u4.no/terms

U4. (s/f). U4 Anticorruption Resource Centre. Obtenido de Glossary: https://www.u4.no/terms

United Nations. (2004). Office of drugs and crime. Recuperado el Febrero de 2021, de https://www.unodc.org/documents/mexicoandcentralamerica/publications/Corrupcion/Convencion_de_las_NU _contra_la_Corrupcion.pdf

UNODC. (2019). Gender-related Judicial Integrity Issues. Vienna, Austria: Thw global judicial integrity network.

Villoria, M. (2002). La corrupción judicial: razones de su estudio, variables explicativas e instrumentos de combate en España. VII Congreso Internacional del CLAD sobre la Reforma del Estado y de la Administración Pública (págs. 8-11). Lisboa: CLAD.

Warren, M. (abril de 2004). What does corruption mean in a Democracy? American Journal of Political Science, 48(2), 328-343.

World Bank. (s/f). Helping Countries Combat Corruption: The Role of the World Bank. Recuperado el 7 de Octubre de 2020, de The borld bank group: http://www1.worldbank.org/publicsector/anticorrupt/corruptn/cor02.htm\#note1

Yusuph, K. (enero de 2016). Sextortion in Education Sector and Response to Criminal Legal System in Tanzania - A Review. Asia Pacific Journal of Education, Arts and Sciences, 3(1), 56-63.

Zahiragic, A., Mahic, A., Pasic, M., Cosic, J., Sacirovic, E., Kadribasic, A., \& Susmel, J. (2011). Fighting sextortion: Toolkit. 